\title{
Long-term adverse effects of intramuscular oil injection
}

\author{
Jacob Juel, ${ }^{1}$ Dorthe Vestergaard Grejsen, ${ }^{2}$ Manan Pareek ${ }^{3}$
}

'Department of Plastic Surgery, Aalborg Universitetshospital, Aalborg, Denmark

${ }^{2}$ Department of Pathology, Zealand University Hospital, Roskilde, Denmark

${ }^{3}$ Heart \& Vascular Center, Brigham and Women's Hospital, Boston, Massachusetts, USA

\section{Correspondence to} Dr Manan Pareek, mananpareek@dadlnet.dk

Accepted 1 May 2017

\section{DESCRIPTION}

A 33-year-old male former bodybuilder presented with painful deformities located to his arms. Roughly a decade ago, he had injected liquid paraffin into his biceps and triceps as a shortcut to achieve muscular enhancement. Today, some of the oil has descended to the forearms, leaving him with painful swellings (paraffinomas) (figure 1) and paraesthesia. MRI revealed localised intramuscular distribution of liquid paraffin in the upper arm muscles (figure 2) and diffuse and localised subcutaneous distribution in the forearms. The patient is currently reviewed regularly as an outpatient and is still able to work as an engineer. A careful history has not revealed any overt systemic complications related to the injections and, so far, he has not required active treatment for his condition.

Site enhancement oils or muscle fillers are liquid compounds of medium-chain triglycerides, local anaesthetics and alcohol that can be injected into muscles to enlarge their size or to alter their shape. ${ }^{1-3}$ Commonly utilised options include paraffin and synthol. ${ }^{1}$ The medical uses of paraffin include skin care and as a laxative, but when injected intramuscularly, complications such as paraffinomas (chronic sclerosing lipogranulomas), ulcerations, infection, systemic embolism and an often-negated irreversible muscle damage may develop within weeks or up to several years after abuse. ${ }^{2}$ Sadly, no curative treatment is available, but surgery, corticosteroids, compressions or antibiotics may be required, depending on the presentation. ${ }^{3}$ Surgery should be reserved for the most severe cases, as it may further reduce functional performance. Vigilance is imperative for surgeons treating this condition, but even more so for those considering such cosmetic doping, given the

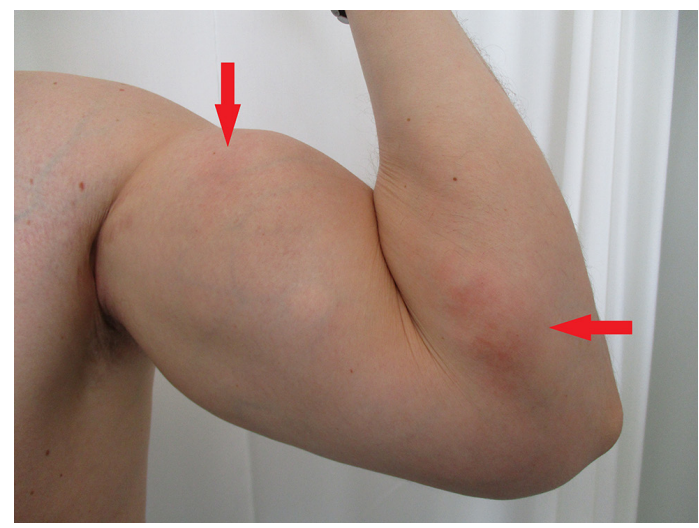

Figure 1 Muscular hypertrophy and swellings (arrows) after liquid paraffin injection.

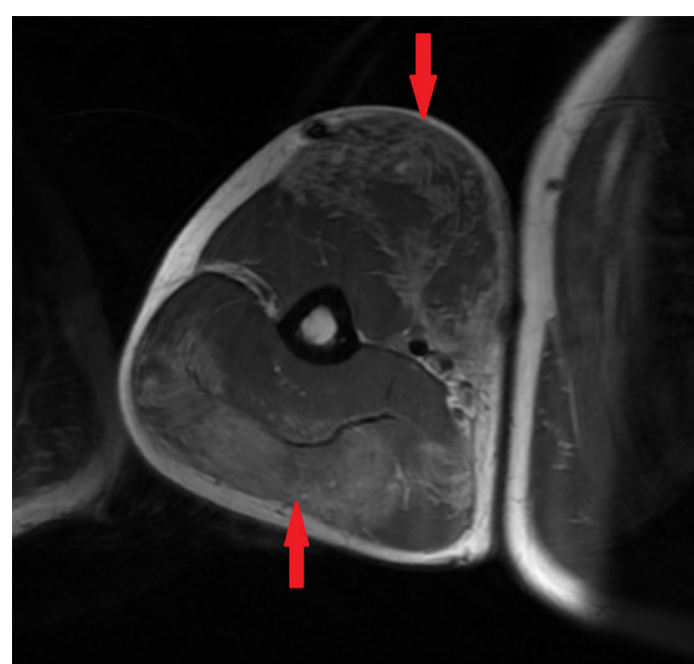

Figure 2 MRI showing localised intramuscular distribution of liquid paraffin (arrows) in the upper arm.

Learning points

- Site enhancement oils, for example, paraffin and synthol, are injected into muscles for augmentation purposes.

- Destructive complications may develop several years after (ab)use.

- No curative treatment is available, but surgery may be required for palliative purposes.

possibility of permanent destructive complications, even with short-term use. ${ }^{2}$

Contributors JJ wrote the initial draft. JJ, DVG and MP participated in collecting patient data, reviewing the literature, interpretation of clinical findings, critical revision of the manuscript for important intellectual content and approval of the final version.

Competing interests None declared.

Patient consent Obtained.

Provenance and peer review Not commissioned; externally peer reviewed.

(C) BMJ Publishing Group Ltd (unless otherwise stated in the text of the article) 2017. All rights reserved. No commercial use is permitted unless otherwise expressly granted.

\section{REFERENCES}

1 Figueiredo VC, Silva PR. Cosmetic doping-when anabolicandrogenic steroids are not enough. Subst Use Misuse 2014:49:1163-7.

2 Banke IJ, Prodinger PM, Waldt S, et al. Irreversible muscle damage in bodybuilding due to long-term intramuscular oil injection. Int J Sports Med 2012;33:829-34.

3 Schäfer CN, Hvolris J, Karlsmark T, et al. Muscle enhancement using intramuscular injections of oil in bodybuilding: review on epidemiology, complications, clinical evaluation and treatment. European Surgery 2012;44:109-15. 
Copyright 2017 BMJ Publishing Group. All rights reserved. For permission to reuse any of this content visit http://group.bmj.com/group/rights-licensing/permissions.

BMJ Case Report Fellows may re-use this article for personal use and teaching without any further permission.

Become a Fellow of BMJ Case Reports today and you can:

- Submit as many cases as you like

- Enjoy fast sympathetic peer review and rapid publication of accepted articles

Access all the published articles

- Re-use any of the published material for personal use and teaching without further permission

For information on Institutional Fellowships contact consortiasales@bmjgroup.com

Visit casereports.bmj.com for more articles like this and to become a Fellow 